\title{
Identification of Thyroid Stimulating Hormone Receptor-specific T Cells in Graves' Disease Thyroid Using Autoantigen-transfected Epstein-Barr Virus- transformed B Cell Lines
}

\author{
Raymond J. Mullins, Shara B. A. Cohen, Louise M. C. Webb, Yuti Chernajovsky, Colin M. Dayan, Marco Londei, \\ and Marc Feldmann \\ The Mathilda and Terence Kennedy Institute of Rheumatology, Sunley Division, Hammersmith, London W6 8LW, United Kingdom
}

\begin{abstract}
The importance of thyrotropin receptor (TSHR) agonist antibodies in the manifestations of Graves' disease (GD) is recognized. There are, however, no convincing reports of TSHR-specific $T$ cells. We have previously cloned $T$ cells specific for thyroglobulin and thyroid peroxidase (TPO) from GD lymphoid infiltrates and used autologous EBVtransformed B cell lines (EBVL) transfected with an expression vector encoding TPO to efficiently detect TPO-specific T cells. Here we used EBVL transfected with TSHR to seek TSHR-specific $T$ cells in the GD infiltrates, after cloning the in vivo activated $T$ cells without antigen. 3 out of 30 clones responded vigorously and reproducibly to EBVL-TSHR, with a mean stimulation index $>7$. Their release of IL-2, IL-4, and IL-10 after stimulation with soluble anti-CD3 and phorbol ester was indistinguishable from the other clones from this thyroid. However, they produced relatively little IFN $\gamma$ (median IL-4/IFN $\gamma$ ratio of 0.80 ) compared with the other clones (median IL-4/IFN $\gamma$ ratio 0.06). Thus, this new potent method of antigen presentation, using autoantigentransfected EBVL, has permitted the first unequivocal identification of TSHR T cells in GD thyroid, with distinct Th0/ Th2 characteristics, unlike previously cloned TPO-responsive cells which have Th1 characteristics. (J. Clin. Invest. 1995. 96:30-37.) Key words: cytokines - autoimmunity • Th1/Th2 cells $\bullet$ interleukin-4 $\cdot$ CD4 $^{+} \mathbf{T}$ cells
\end{abstract}

Address correspondence to Professor Marc Feldmann, Kennedy Institute of Rheumatology, Sunley Division, 1 Lurgan Avenue, London W6 8LW, United Kingdom. Phone: 0181-741-8966; FAX: 0181-563-0399. Colin M. Dayan's present address is the Department of Medicine, Bristol Royal Infirmary, Bristol BS2 8HW, United Kingdom. Raymond J. Mullins' present address is the Centenary Institute of Cancer Medicine and Cell Biology, Locked Bag Number 6, Newtown NSW 2042, Australia.

Received for publication 28 November 1994 and accepted in revised form 13 March 1995.

1. Abbreviations used in this paper: APC, antigen presenting cells; EBVL, EBV-transformed B cell lines; EBVL-CAT, EBVL transfected with pREP4-CAT; EBVL-TPO, EBVL transfected with pREP4-TPO; EBVL-TSHR, EBVL transfected with pREP4-TSHR; GD, Graves' disease; HS, human serum; ICAM-I, intercellular adhesion molecule-I; SI, stimulation index; TCR, T cell receptor; TEC, thyroid epithelium; Tg, thyroglobulin; TPO, thyroid peroxidase; TSH, thyroid stimulating hormone (thyrotropin); TSHR, thyroid stimulating hormone receptor.

J. Clin. Invest.

(c) The American Society for Clinical Investigation, Inc.

0021-9738/95/07/0030/08 \$2.00

Volume 96, July 1995, 30-37

\section{Introduction}

Graves' disease (GD) ${ }^{1}$ is a common cause of organ-specific autoimmunity in humans. Autoantibodies against three major autoantigens, thyroid peroxidase (TPO), thyroglobulin ( $\mathrm{Tg}$ ), and the thyroid stimulating hormone (thyrotropin) receptor (TSHR) are detected in serum from the majority of patients with GD and are frequently used to confirm the diagnosis. In the case of the anti-TSHR response, the agonist autoantibodies are pathogenic and responsible for the clinical manifestations of disease, by mimicking the effects of TSH and inducing the overproduction of thyroid hormone (for review see reference 1).

Less is known, however, about the $\mathrm{T}$ cell response to these autoantigens. We have previously shown that antigen-specific $\mathrm{T}$ cells may be cloned from diseased thyroid tissue and that at least some of these $\mathrm{T}$ cells respond to thyroid epithelium, Tg, or $\operatorname{TPO}(2,3)$. Additional clones were found in the latter study to be unresponsive to TPO or Tg, but proliferated vigorously when exposed to autologous thyroid epithelium (TEC). Progress was hampered by limitations in obtaining sufficient autologous antigen presenting cells (APC) from individual patients for our studies and by nonspecific stimulation or inhibition of proliferation using recombinant autoantigen. These problems led us to consider an alternative approach of presenting the autoantigen: the transfection of cDNA encoding autoantigen into autologous EBV-transformed B cell lines (EBVL) (4). The capacity of these cells to effectively present TPO to specific $\mathrm{T}$ cells ( even at low APC/T cell ratios) confirmed that like other cell surface proteins, membrane-bound TPO is internalized and its peptides are recycled with class II molecules $(5,6)$. Unfortunately, no TSHR-specific T cells were identified at that time, consistent with the lack of convincing data in the literature. It was unclear, however, whether these findings were due to the absence of TSHR-specific T cells in that patient alone or in Graves' disease per se. The presence of TSHR autoantibodies might be explicable on the basis of "intermolecular help" of TSHR-specific B cells by TPO-specific T cells, since TSHR and TPO are "linked molecules" by virtue of their coexpression on TEC (7).

The availability of clinical material from additional patients provided us with the opportunity to study the antigen specificity and functional characteristics of additional $\mathrm{T}$ cell clones. In this study, autologous EBV-transformed B cell lines from a second patient with active GD at the time of surgery were successfully transfected with expression plasmids encoding the cDNA for full-length human TPO or TSHR. A number of these clones responded vigorously and reproducibly to EBVL-TSHR (but not to EBVL-TPO) and were distinguishable from the remaining clones by their relatively minor release of IFN $\gamma$ after stimulation with OKT3 antibody and phorbol myristate acetate (PMA). 


\section{Methods}

Reagents. Single donor human AB positive sera (HS) and fetal calf serum (FCS) were obtained from the North London Blood Transfusion Service (Edgware, Middlesex) and Gibco Laboratories (Paisley, Scotland), respectively. Recombinant human IL-2 was kindly donated by Dr. P. Lomedico (Hoffman-La Roche, Nutley, NJ). PMA was purchased from Sigma Immunochemicals (St. Louis, MO).

Cells and cell lines. Infiltrating mononuclear cells were extracted from the thyroidectomy specimen of a 28-yr-old female (T8) with GD, HLA typed as A2, 24; B8, 40; Cw2, w7; DR2, 3; DQw1, w2. High titer $\mathrm{Tg}$ and TPO autoantibodies were noted at the time of diagnosis. Unusually, the patient had active GD at the time of surgery, having declined prior medical therapy or treatment with radioactive iodine. Extracted T cells were cloned under limiting dilution conditions, in the absence of antigen by stimulation with irradiated allogeneic peripheral blood mononuclear cells (PBMC) (North London Blood Transfusion Service), anti-CD3 (OKT3; American Type Culture Collection, Rockville, MD, antibody, and IL-2 as described previously (3). T cells were also cloned from the thyroids of two other patients with active GD, CX81 (4) and patient T13. All autoantigen-responsive T cell clones identified in this study constitutively expressed the cell surface markers CD3, CD4, and $\alpha \beta$ T cell receptor (TCR). PBMC were isolated from the same patient by centrifugation over Ficoll (Lymphoprep; Nycomed, Oslo, Norway) and blood-derived B cells were transformed with EBV as described previously (8). EBV-transformed lines (EBVL) were maintained in medium containing 10\% FCS in RPMI 1640 (Gibco Laboratories, Grand Island, NY).

Cell marker analysis. Flow cytometry was used to define the surface expression of CD3, CD4, CD8, and TCR V $\alpha$ and $V \beta$ on the surface of lymphocytes, and of HLA class II (DR, DP, and DQ), intercellular adhesion molecule-I (ICAM-I = CD54), CD28 ligand, and TPO on the surface of EBVL. Cells were either incubated on ice with the directly conjugated mAbs anti-CD3 (energy-coupled dye, ECD), anti-CD4 (FITC), or anti-CD8 (PE) purchased from Becton Dickinson (Fullerton, CA), or with optimal concentrations of unconjugated antibodies directed against HLA-DR (HB 55; American Type Culture Collection), HLADP (B7/21; Dr. I. Trowbridge, Salk Institute, La Jolla, CA), HLA-DQ (SPVL3; Dr. H. Spits, Netherlands Cancer Institute, Amsterdam, The Netherlands), ICAM-I (1H4; Dr. A. Boyd, Melbourne, Australia), $\alpha \beta$ TCR (BMA 031; Dr. R. Kurrle, Boehringer Mannheim, Mannheim, Germany), human TPO (A3; Dr. P. Banga, Kings College School of Medicine and Dentistry, London, United Kingdom), and the CD28 ligand (BB1; Dr. J. Ledbetter, Seattle, WA). Monoclonal antibodies used in this study are as follows: the directly conjugated monoclonal antibodies CD3-ECD (Coulter Corp., Hialeah, FL), Leu3a anti-CD4, and Leu2a anti-CD8, were purchased from Becton Dickinson. E22E7.2 (IgM) anti-V $\beta 2$, LE-89 ( $\left.\operatorname{IgG}_{2 \mathrm{a}}\right)$ anti-V $\beta 3$, JU-74 $\left(\mathrm{IgG}_{1}\right)$ anti-V $\beta 13.3$, BA62 $\left(\operatorname{IgG}_{2 b}\right)$ anti-V $\beta 17$, E17.5F3.15.13 anti-V $\beta 19\left(\operatorname{IgG}_{1}\right)$ were from Dr. F. Romagne (Immunotech, Marseille, France). $421 \mathrm{Cl}\left(\mathrm{IgG}_{1}\right)$ antiV $\beta 5.2 / 3$, W112 (IgG $\left.{ }_{1}\right)$ anti-V $\beta 5.3$, OT145 (IgG 1 anti-V $\beta 6.7 \mathrm{a}, 16 \mathrm{G} 8$ $\left(\mathrm{IgG}_{1 \mathrm{~b}}\right)$ anti-V $\beta 8$, S511 ( $\left.\mathrm{IgG}_{2 \mathrm{~b}}\right)$ anti-V $\beta 2$, F1 $\left(\mathrm{IgG}_{2 \mathrm{a}}\right)$ anti-V $\alpha 2$, WT31 $\left(\mathrm{IgG}_{1}\right.$ ) anti- $\alpha \beta$, anti-V $\beta 5.1, \mathrm{LC} 4$ ( $\mathrm{IgG}_{1}$ ) were from Dr. P. Kung (T Cell Sciences, Cambridge, MA). Anti-V $\beta 13.1$ and anti-V $\beta 13.2$ were from Dr. P. Marrack (Denver, CO); $6 \mathrm{D} 6\left(\mathrm{IgG}_{1}\right)$ anti-V $\alpha 12$ was from Dr. M. Brenner (Boston, MA); anti-V $\beta 5.1 \mathrm{LC}\left(\mathrm{IgG}_{1}\right)$ was from T Cell Sciences; anti-V $\beta 7.13 \mathrm{G} 5$ ( $\left.\operatorname{IgG}_{2 b}\right)$ was from Prof. A. McMichael (Institute Molecular Medicine, Oxford) anti-V $\beta$ 9.1 MKB P1 ( IgG $\left._{1}\right)$ was from Dr. Kanagawa (St. Louis, MO); anti-V $\beta$ 11.1/11.2 C21 $\left(\mathrm{IgG}_{2 \mathrm{e}}\right)$ and anti-V $\alpha 24 \mathrm{C} 15\left(\mathrm{IgG}_{1}\right)$ were from Dr. A. Lanzavecchia (Basel, Switzerland).

The IgG 1 mAb HB 10656 (from DNAX, Palo Alto, CA via American Type Culture Collection, directed against murine IL-6) was used to control for nonspecific binding. Cells were then washed and incubated with FITC-conjugated goat anti-mouse antibody (Coulter Corp.). Stained cells were washed in PBS and fixed in 3\% paraformaldehyde in PBS for 30 min, then washed and resuspended in PBS and stored in the dark until 10,000 cells were analyzed on a FACStar Plus flow cytometer (Becton Dickinson).

Transfection of EBV-transformed $B$ cell lines with PREP4-TPO and pREP4-TSHR. $10^{7}$ autologous EBVL were transfected with the expression vectors PREP4-TPO or pREP4-TSHR by electroporation as described previously (4). Successfully transfected cells were selected by growth in hygromycin-containing medium (Boehringer Mannheim) and maintained at a final concentration of $150 \mu \mathrm{g} / \mathrm{ml}$ in RPMI 1640 containing 10\% FCS. Cell surface expression of transfected TPO by EBVL transfected with pREP4-TPO (EBVL-TPO) was confirmed by flow cytometry using the anti-TPO mAb A3 (8). Surface expression of TSHR was assessed by comparing the binding of highly purified bovine ${ }^{125} \mathrm{I}$ labeled TSH (RSR, Cardiff, United Kingdom) to EBVL transfected with pREP4-TSHR (EBVL-TSHR) or untransfected EBVL as described previously (4).

Culture conditions. Thyroid-derived $\mathrm{T}$ cell clones were maintained in 10\% heat-inactivated HS in RPMI independently of antigen by restimulation every 10-14 d with OKT3, IL-2, and irradiated allogeneic PBM followed by expansion in IL-2-containing medium (2). At no time were clones or lines exposed to specific antigen, except in proliferation assays. Proliferative responses to transfected and untransfected EBVL were performed after fixation of these cells in $0.05 \%$ glutaraldehyde (9). Unless otherwise indicated, 50,000 EBVL and 20,000 T cells were then dispensed into each triplicate well of round-bottomed 96-well culture plates (Nunc, Kamstrup, Denmark). In some cultures, IL-2 was added at a final concentration of $5 \mathrm{ng} / \mathrm{ml}$ after $48 \mathrm{~h}$ of incubation.

Background levels of cellular proliferation were assessed by cultures of EBVL alone and T cells alone, and all assays included the positive control of T cells plus $\mathrm{IL}-2(10 \mathrm{ng} / \mathrm{ml})$. After $72 \mathrm{~h}$ at $37^{\circ} \mathrm{C}$ in an atmosphere of $5 \% \mathrm{CO}_{2}$ in air, cultures were pulsed with $0.5 \mu \mathrm{Ci}$ per well of methyl $\left[{ }^{3} \mathrm{H}\right]$ thymidine (Amersham International, Amersham, United Kingdom) and harvested $6 \mathrm{~h}$ later onto glass fiber filters. Scintillation counting was performed in a LKB Betaplate counter (Pharmacia LKB Biotechnology, Uppsala, Sweden), and $\left[{ }^{3} \mathrm{H}\right]$ thymidine incorporation was expressed as the mean $\mathrm{cpm} \pm \mathrm{SD}$ of triplicate cultures. Stimulation indices (SI) were calculated using the formula: $\mathrm{SI}=\mathrm{cpm}$ ( $\mathrm{T}$ cells + transfected EBVL)/cpm (T cells + untransfected EBVL).

Cytokine production by $T$ cell clones. $T$ cell clones were stimulated to release cytokines $12-14 \mathrm{~d}$ after the last OKT3 stimulation. After adjusting their concentration to $10^{6} / \mathrm{ml}$, T cells were cultured in $10 \%$ HS containing soluble OKT $3,1 \mu \mathrm{g} / \mathrm{ml}$, and PMA, $10 \mathrm{ng} / \mathrm{ml} .24 \mathrm{~h}$ later, supernatants were harvested by centrifugation and stored at $-20^{\circ} \mathrm{C}$ until assayed in specific capture ELISA. Supernatants from all the clones were assayed in parallel on the same day for IFN $\gamma$ (kindly provided by Dr. D. Novick, Weizmann Institute, Rehovot, Israel; clone 3.3 for coating, biotinylated clone 166.5 for detection, using rhIFN $\gamma$ in $10 \% \mathrm{HS}$ in RPMI as standard), IL-4 (kindly provided by Dr. F. di Padova, Sandoz Pharma AG, Basel, Switzerland; clone 1-41-1 for coating, biotinylated clone 1-38-10 for detection, and thIL-4 in 10\% HS in RPMI as standard), and IL-10 (kindly provided by Dr. K. Moore and Dr. J. Abrams, DNAX; clone 9D7 for coating, biotinylated clone 12G8 for detection and rhIL-10 diluted in 10\% HS in RPMI as standard). The sensitivities of these assays are 120,40 , and $120 \mathrm{pg} / \mathrm{ml}$, respectively. The concentration of IL-2 was estimated using a standard CTLL bioassay with a sensitivity of $200 \mathrm{pg} / \mathrm{ml}$. T cells were classified on the basis of their IL-4 and IFN $\gamma$ synthesis (10-12) into Th1 (IFN $\gamma$ alone or IL-4:IFN $\gamma$ $<0.1$ ); Th2 (IL-4 alone or IL-4:IFN $\gamma>2.0$ ); Th0 (release of both $\mathrm{IL}-4$ and IFN $\gamma$ with the IL-4:IFN $\gamma$ ratio between 0.1 and 2.0); naive pTH (release IL-2 but no detectable IL-4 or IFN $\gamma$ ).

Statistical analysis. Statistical analysis was performed using Statview II for the Macintosh computer, using the Mann Whitney U test for paired data and the Kruskal-Wallis test for comparing data from multiple groups.

\section{Results}

Transfection of pREP4-TSHR and pREP4-TPO. Confirmation of transfection was assessed by assaying for the presence of the 

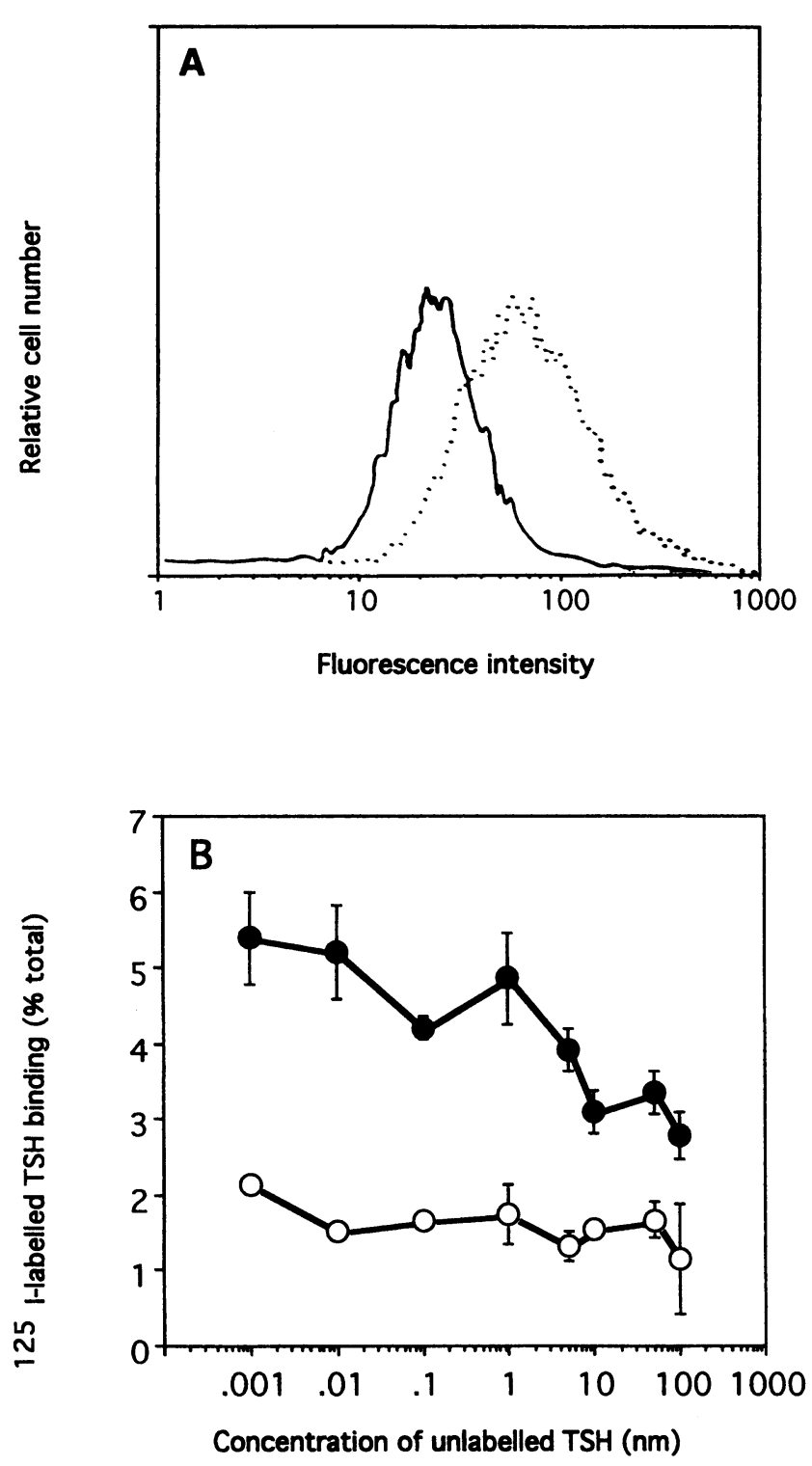

Figure 1. Confirmation of transfection of EBVL. (A) Surface expression of TPO was assessed by flow cytometry after staining EBVL-TPO ( $b r o$ ken line) and control untransfected EBVL (solid line) with the TPOspecific mAb A3. (B) Surface expression of TSHR was assessed by measuring the binding of ${ }^{125} \mathrm{I}$-TSH to EBVL-TSHR cells (closed circles) and to control untransfected EBVL cells (open circles) in the presence of titrated concentrations of unlabeled TSH.

relevant protein. Cell surface expression of TPO was demonstrated by flow cytometry using the TPO-specific mAb A3 to stain the surface of TPO-transfected cells (Fig. $1 A$ ). No binding was observed when cells were stained with the control antibody (data not shown) or when irrelevant transfectants were stained with the same antibody (Fig. $1 \mathrm{~A}$ ). In the absence of suitable mAbs, surface expression of TSHR was demonstrated by the binding of ${ }^{125} \mathrm{I}$-labeled TSH to pREP4-TSHR, but not to control untransfected cells, and its inhibition by unlabeled TSH (Fig. $1 B$ ). All EBVL generated, whether transfected or not, were found to be indistinguishable from each other in terms of expression of class II antigen (HLA-DP, HLA-DQ, and HLA-DR), the adhesion molecule ICAM-I, and the T cell costimulatory
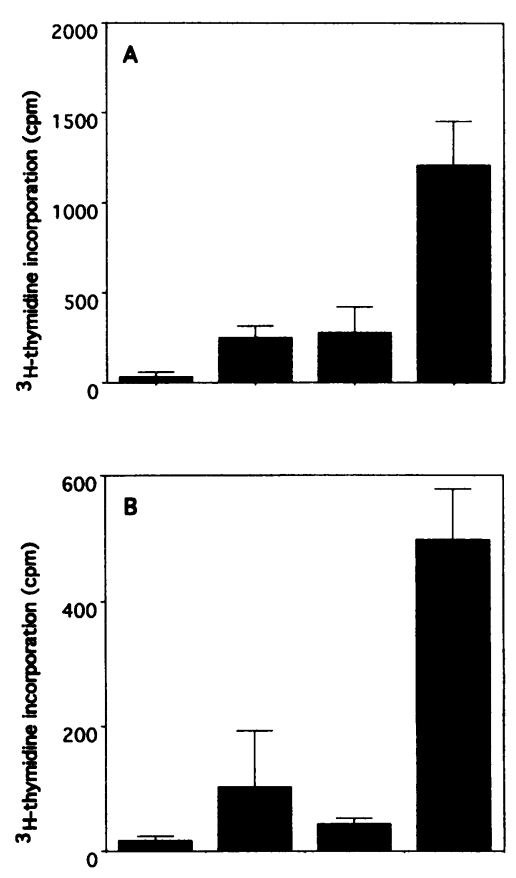

Figure 2. Proliferative response of thyroid-derived $T$ cell clones to transfected TSHR. The incorporation of $\left[{ }^{3} \mathrm{H}\right]-$

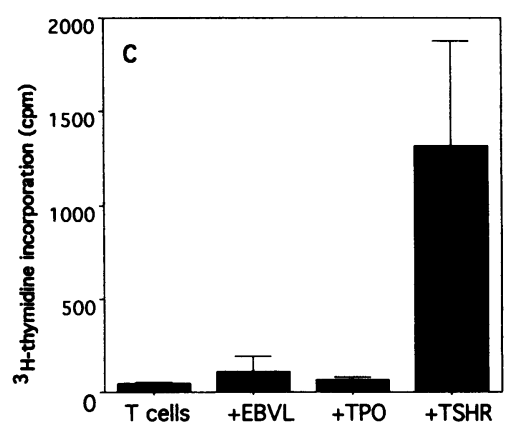
thymidine into thyroidderived $\mathrm{T}$ cell clones was measured after $3 \mathrm{~d}$ of stimulation by intact fixed untransfected EBVL, EBVL-TPO, or EBVL-TSHR compared with unstimulated $T$ cells and expressed as the mean cpm of triplicate cultures \pm SD. $(A)$ Clone 8.6, $(B)$ clone $8.18,(C)$ clone 8.21.

molecule termed BB1, the CD28 ligand (CD80; data not shown), as described in a previous report (4).

Autoantigen presentation by transfected EBVL: recognition by thyroid-derived $T$ cell clones. The generation of continuous cell lines expressing stable levels of surface TPO or TSHR and their ability to present transfected antigen (4) enabled us to study the antigen responsiveness of uncloned thyroid infiltrate as well as the specificity of 30 thyroid-derived clones. Clones were cultured in the presence of untransfected EBVL, EBVLTPO, or EBVL-TSHR; the former served as a control for antiEBV responses whereas the latter two transfected lines served as internal antivector controls. All clones were $\mathrm{CD} 4^{+}, \mathrm{CD}^{+}$, and TCR $\alpha \beta^{+}$and were tested on a minimum of three separate occasions. On the basis of their proliferative response, clones could be divided into three distinct groups. The first group (of 16 clones) was unstimulated by any EBVL above background levels while retaining a vigorous response to IL-2 (data not shown). As found in previous cloning studies $(3,10,11)$, the second group (of 11 clones) responded comparably to all 3 EBVL as well as autologous PBL where tested (data not shown), consistent with a mixed leukocyte reaction. Finally, the third group (clones $8.6,8.18$, and 8.21 ) proliferated only in response to EBVL-TSHR (Fig. 2). Surprisingly, in this individual, no clones (of 30) responded to EBVL-TPO, unlike the results of a previous GD patient studied extensively $(3,4)$. 

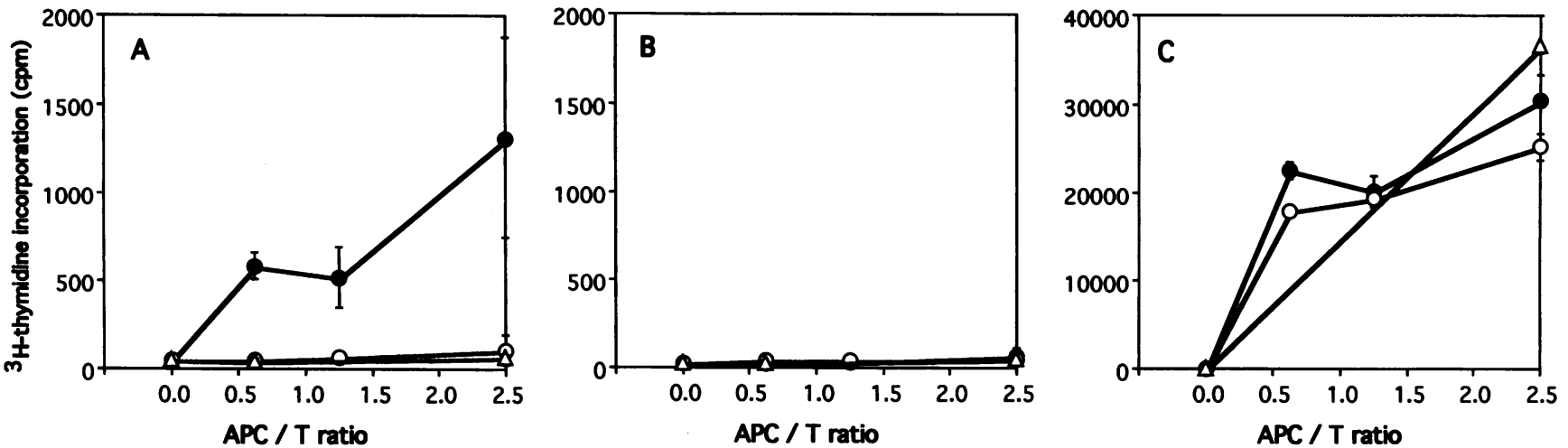

Figure 3. Antigen presentation by transfected EBVL. The efficacy of antigen presentation by fixed TSHR-transfected EBVL was assessed by stimulating 20,000 T cells of the thyroid-derived clones with titrated numbers of EBVL-TSHR (closed circles), EBVL-TPO (open triangles), or control untransfected EBVL (open circles). Proliferation is expressed as the mean cpm of triplicate cultures \pm SD. $(A)$ Clone 8.21, $(B)$ clone 8.19, (C) clone 8.28. All clones responded vigorously to IL-2 (data not shown).

The proliferative responses of clones $8.6,8.18$, and 8.21 were specific for EBVL transfected with TSHR. When 20 separate, independent assays were performed, the TSHR responsiveness of these 3 clones was maintained and was reproducible, with an overall mean, median, and range of SI values of 7.5 , 4.9, and 3.3-15.1, respectively. Furthermore, there was a clear relationship between the number of EBVL-TSHR present and the proliferative response observed in TSHR-specific (Fig. 3 $A$ ) but not irrelevant clones (Fig. $3 B$ and $C$ ). Finally, the clones identified were distinct and not "sister" clones; analysis of TCR phenotype by flow cytometry demonstrated heterogeneity for clones $8.6(\mathrm{~V} \beta 3), 8.18$ (not definable), and 8.21 $(\mathrm{V} \beta 13.2, \mathrm{~V} \alpha 24)$.

The proliferative responses to EBVL-TSHR were relatively minor compared with those detected by TPO-specific clones from a previous patient with active Graves' disease, CX81 (4). Since it was conceivable that this might be secondary to poor IL-2 release by TSHR-stimulated Th2-like T cells, these clones were restimulated with EBVL in the presence or absence of exogenous $\mathrm{IL}-2$ added at $48 \mathrm{~h}$. Preliminary experiments demonstrated that these conditions were optimal for minimizing the enhancement of background counts. As shown in Fig. 4, responses to EBVL-TSHR were amplified 10-fold in the presence of IL-2 (and to a lesser extent in the uncloned infiltrate). Responses in previously unresponsive or panresponsive clones, however, were not altered.

Cytokine release by $T$ cell clones. Since secretion of IL-2 by human clones (unlike murine clones) does not always parallel that of IFN $\gamma(12,13)$, T cells were classified on the basis of their IL-4 and IFN $\gamma$ synthesis $(12,14)$. In common with other human studies (15-17), few stimulated clones released IFN $\gamma$ or IL-4 exclusively to be classified as Th1 (clones 8.11, 8.19 , and 8.29) or Th2 (clones 8.10, 8.13, 8.21, and 8.23) cells, respectively. Instead, the majority released a mixture of IL-4 ( $80 \%$ of clones), IFN $\gamma$ ( $83 \%$ of clones), IL-10 ( $80 \%$ of clones), or IL-2 (all clones), with one or another cytokine being predominant, particularly IFN $\gamma$ in 21 of 30 clones (Table I).

A different pattern emerged, however, when the data were reanalyzed on the basis of the antigen specificity of the cloned $T$ cells. Whereas TSHR-specific clones could not be distinguished from other clones by their level of $I L-2, I L-4$, or $I L-10$ release
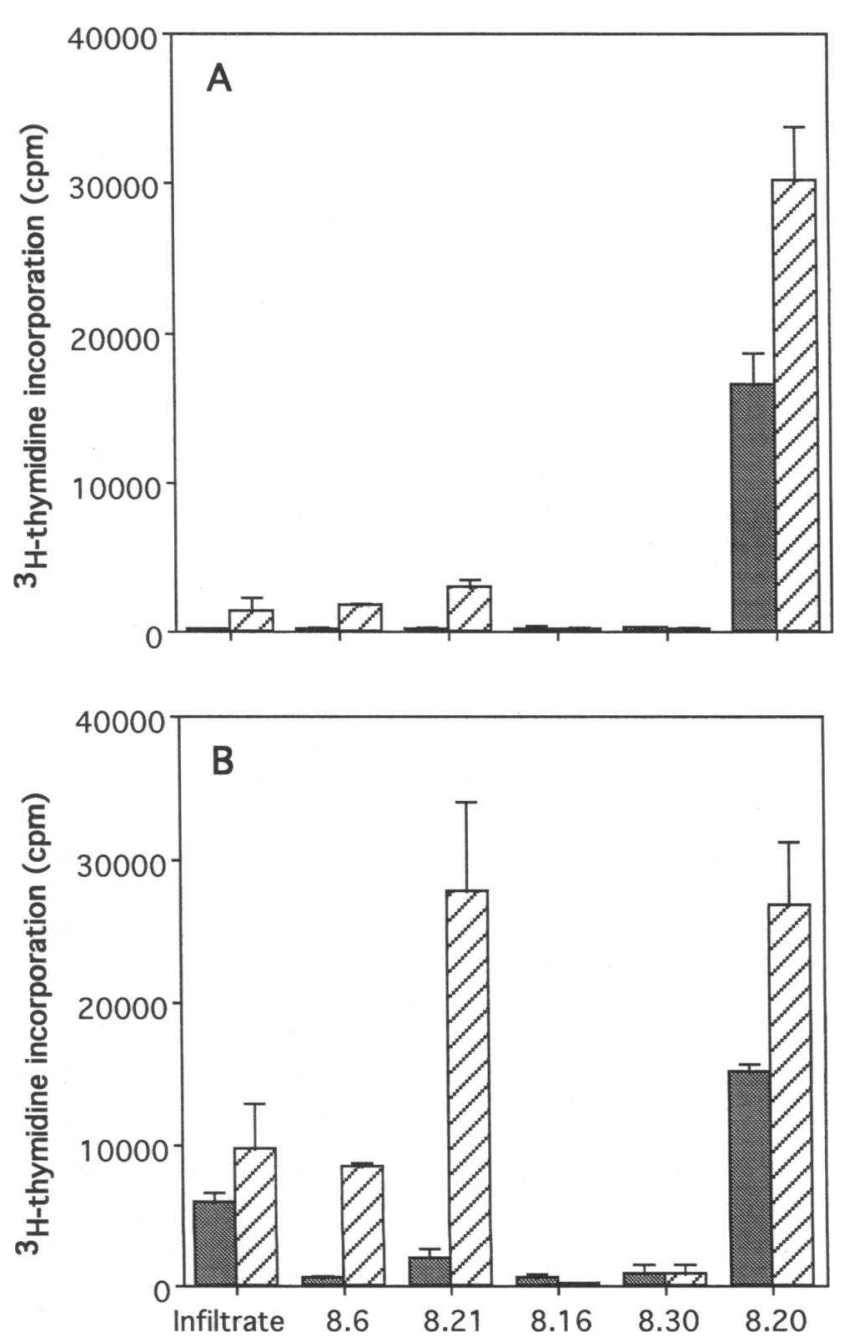

Figure 4. The effect of IL-2 on the proliferative response to transfected TSHR. The incorporation of $\left[{ }^{3} \mathrm{H}\right]$ thymidine into thyroid-derived $\mathrm{T}$ cell uncloned infiltrate and $\mathrm{T}$ cell clones was measured after $3 \mathrm{~d}$ of stimulation by intact fixed untransfected EBVL (shaded bars) or EBVL-TSHR (hatched bars) in the $(A)$ absence or $(B)$ presence of $5 \mathrm{ng} / \mathrm{ml}$ of $\mathrm{IL}-2$ added after $48 \mathrm{~h}$. Proliferation is expressed as the mean cpm of triplicate cultures \pm SD. 
Table I. Cytokine Release by Stimulated Thyroid-derived T Cell Clones

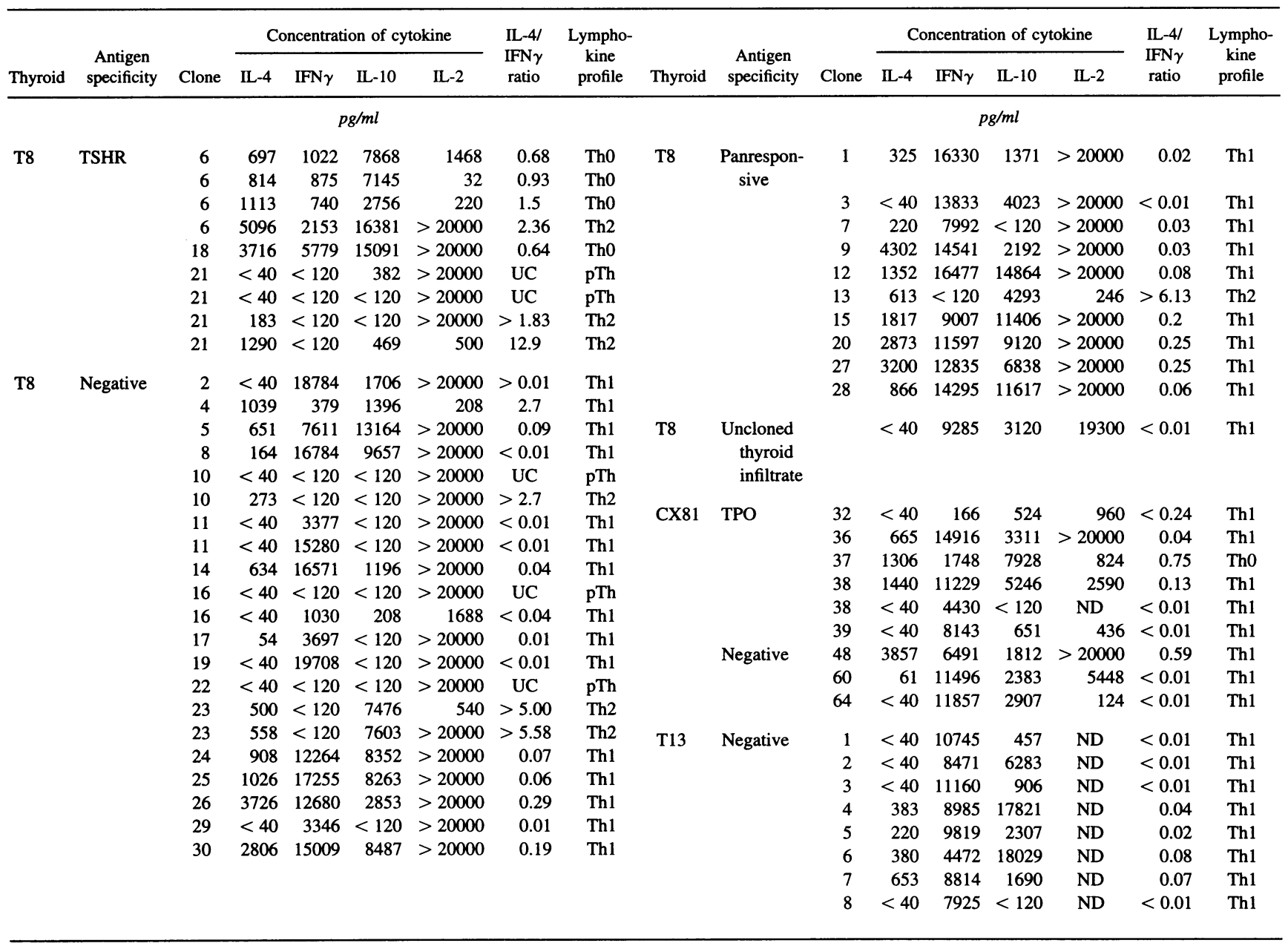

After stimulation with soluble OKT3 plus PMA, culture supernatants were harvested and assayed for cytokine production by CTLL bioassay (IL-2) or by specific ELISA (the remaining cytokines) and tested in parallel. UC, unable to be calculated; ND, not done. These are the results from multiple experiments.

with stimulation $(P>0.13$ in all cases $)$, they produced significantly less IFN $\gamma$ than EBVL unresponsive or panresponsive clones from the same thyroid (Table I). For example, the median concentrations of IFN $\gamma$ released by TSHR-specific clones, unresponsive clones, and panresponsive clones were $640,6,410$, and $14,295 \mathrm{pg} / \mathrm{ml}$, respectively $(P=0.01)$, reflected in corresponding median IL-4:IFN $\gamma$ ratios of $0.80,0.08$, and 0.06 . Consistent results were obtained in several experiments.

To determine whether the relatively high IL-4:IFN $\gamma$ ratio was a feature of autoreactive clones per se or restricted to $\mathrm{T}$ cells specific for the TSHR, we compared TSHR-specific clones with thyroid-derived TPO-responsive and autoantigen-negative clones from patient CX81 $(2,4)$ and antigen-negative thyroidderived clones (data not shown) from patient T13. The relatively low release of IFN $\gamma$ by stimulated TSHR-specific T cells remained the only distinguishing feature of this group from any of the five others (Table $\mathrm{I} ; P=0.01$ ).

\section{Discussion}

The identification of autoreactive $\mathrm{T}$ cells and their corresponding antigen is pivotal to understanding the pathogenesis of autoimmune disease. Most studies of human autoimmune disease have attempted to stimulate blood-derived $\mathrm{T}$ cells in vitro by driving them with putative autoantigens such as acetylcholine receptor (18) or myelin basic protein (19). Unfortunately, the finding of autoantigen-responsive $T$ cells in the blood of healthy individuals makes it impossible to determine whether the $\mathrm{T}$ cells identified are ever activated at the site of disease and involved in its pathogenesis or are simply part of the normal precursor pool and were activated in vitro.

Using an alternative approach that we developed, we have shown that $\mathrm{T}$ cells can be cloned from the active site of disease in autoimmune thyroid disease and that many of these clones respond to tissue-specific autoantigens (3). T cells are first expanded in IL-2 to select for in vivo activated cells, then cloned and maintained in the absence of antigen until screening. In this way, $T$ cell clones responsive to at least three thyroid autoantigens have been identified in a patient with active GD (3). The response to thyroid antigens in this patient (CX81) was heterogeneous, with clones responsive to $\mathrm{Tg}$, at least three TPOderived epitopes, and a third group of $\mathrm{T}$ cells specific for autologous TEC (but neither to purified $\mathrm{Tg}$ nor to recombinant TPO) (3).

The lack of a preparation of recombinant TSHR prevented us from fully defining the $T$ cell antigen repertoire in patient 
CX81 at that time. Together with limitations in obtaining sufficient autologous APC for ongoing work, these problems led us to consider an alternative approach to presenting antigen: the transfection of cDNAs encoding TPO or TSHR into autologous EBV-transformed B cell lines (4). When TEC-responsive and -unresponsive clones from patient CX81 were restudied, however, no TSHR-responsive T cells were identified despite the capacity of transfected cells to effectively present the endogenously synthesized TPO antigen to specific T cells (4). This was surprising, in view of the evidence that the thyroid is the major site of autoantibody (including TSHR autoantibody) production in many patients (20-22) and is thus a likely source of TSHR-specific T cells and B cells. Therefore, it was unclear whether these findings were best explained by the absence of TSHR-specific T cells in Graves' disease per se, in patient CX81 alone, or at a frequency too low to be detected by nonantigen-stimulated cloning.

The availability of clinical material from additional patients with active disease provided us with an opportunity to identify additional thyroid $\mathrm{T}$ cell autoantigens and to characterize the function of the corresponding T cells. By transfecting the EBVL of patient T8 with expression vectors encoding the entire TSHR or TPO, continuous lines of autoantigen presenting cells were generated. Transfected EBVL expressed the transmembrane forms of these antigens, as shown by the binding of anti-TPO $\mathrm{mAb}$ and radiolabeled TSH to EBVL-TPO and EBVL-TSHR, respectively (Fig. 1). The capacity of these cells to effectively present TSHR to three $\mathrm{CD} 4^{+} \mathrm{T}$ cell clones and reproducibly stimulate them confirmed that, like other cell surface proteins, including transfected TPO $(4,5)$, TSHR is internalized and its peptides are recycled with class II molecules. The responses to EBVL-TSHR by clones $8.6,8.18$, and 8.21 were not due to release of nonspecific growth factors by this cell line. This is because the EBVL were fixed before use in proliferative assays, thus preventing growth factor release, but also a large number of autologous clones derived from the same thyroid failed to be stimulated by EBVL-TSHR (Fig. $3 A$ ). Furthermore, there was a clear relationship between the number of EBVL-TSHR (but not control EBVL) cells per culture and the proliferative response observed. Finally, there was nothing to distinguish EBVL-TSHR from other lines in terms of class II, ICAM-I, or CD28 ligand expression (data not shown), making it unlikely that the responses seen were a result of nonspecific stimulation by surface molecules. Since the only form of recombinant TSHR available was a nonspecific stimulator of all clones (including those of known irrelevant antigen specificity), confirmatory testing using conventional culture techniques was unfortunately impossible.

It is unclear why the proliferative responses to EBVL-TSHR observed in patient $\mathrm{T} 8$, while reproducible, were relatively minor (median SI $=4.9$, mean $>7$ ) compared with those obtained with TPO-responsive clones from patient CX81 (median SI $=122$ ) in a previous study ( 3 ). One possible clue to the mechanism of the low responses is provided by the observation that proliferative responses to EBVL-TSHR were specifically enhanced in the presence of exogenous IL-2, added at a time to minimize an increase in background counts (Fig. 4). These experiments were prompted by the description of not only murine and human $\mathrm{Th} 2$ clones with low IL-2 synthesis $(23,24)$, but also of allergen-specific human Th2 cell clones whose proliferative response to antigen was dependent on the addition of exogenous IL-2 or IL-4 $(23,25)$. These results are difficult to reconcile with the capacity of these clones to produce IL-2 when exposed to potent stimuli like OKT3 and PMA (Table I). That they may synthesize only small quantities of IL-2 in vivo, or after suboptimal stimulation with fixed EBVL in vitro, cannot be excluded (26).

These results provide insights into why convincing Th2-like TSHR-responsive $\mathrm{T}$ cells may have eluded identification for so long $(27,28)$. As well as the technical problems described, both the method of cloning and the testing procedures used by ourselves and other groups have probably diminished the likelihood of expanding, cloning, and correctly identifying antigen-specific Th2 clones. In addition to its roles as a B cell growth factor and inducer of Th2 cells in primary antigen responses $(29,30), \mathrm{IL}-4$ is a $\mathrm{T}$ cell growth factor and is required by $\mathrm{Th} 2$ cells for their successful expansion and long term maintenance in culture $(23,29,31)$. Not only is the absence of IL4 from culture media (we use recombinant IL-2) likely to have been detrimental, but the use of macrophages rather than $B$ cells or EBVL as feeder cells $(23,32)$ may have impeded the successful expansion and cloning of Th2 cells. Furthermore, the screening procedure itself selects for clones which produce sufficient endogenous IL-2 to be detected by standard proliferation assays; low responses are generally ignored when screening large numbers of clones. The need to induce a Th2 response might also explain the lack of a suitable animal model for GD, since the conventional methods by which animals are vaccinated with antigen in adjuvant, usually complete Freund's adjuvant, preferentially induce a Th1-like response (33).

The initial observation that murine $\mathrm{T}$ cells could be classified on the basis of their cytokine production has been confirmed in a number of human studies of patients suffering from infections, allergic disease, or immunodeficiency (for review see reference 34 ). Human Th1 cells produce predominantly IFN $\gamma$, IL-2, and TNF $\beta$ and mediate delayed hypersensitivity responses, whereas Th2 cells produce mainly IL-4, IL-5, and IL6 and promote the growth and function of $B$ cells. Both subsets may produce $I L-10$ in humans $(12,13,25)$. T cells with a less polarized profile of cytokine release are classified as Th0 and are characteristic of the majority of randomly generated clones in humans. The relationship between these subsets and naive IL-2-producing pTh cells is unclear, but the best evidence is that these differentiate into one or other types during priming $(30,35,36)$. All Th subsets were observed in this study (Table I). In line with previous studies of clones (of unknown antigen specificity) from patients with autoimmune thyroid disease (15, $37,38)$, the majority of thyroid-derived clones from patients $\mathrm{CX81}, \mathrm{T} 13$, and $\mathrm{T} 8 \mathrm{had}$ a clear predominance of IFN $\gamma$ over IL-4 release characteristic of a Th1 lymphokine profile. On the other hand, if one restricts analysis to $\mathrm{T}$ cells responsive to thyroid autoantigens (in our studies), a different pattern emerges. For example, four of the five TPO-specific clones from patient CX81 displayed a Th1 lymphokine profile (the remaining clone was more characteristic of $\mathrm{Th} 0$ ), whereas cytokines released by the three TSHR-responsive clones from patient T8 were more characteristic of Th0 or Th2 cells (Table I). Indeed, the relatively low IFN $\gamma$ release and high IL-4:IFN $\gamma$ ratios were the only features to distinguish these clones from those of any other group.

The heterogeneity of cytokine release by both TPO-responsive and TSHR-specific T cell clones is of particular interest and has interesting implications for understanding the pathogenesis of GD. The reason for the compartmentalization of three 
TSHR-responsive clones with a broadly similar cytokine profile is uncertain, but one possible explanation is that they may represent functional Th2 cells which assist the production of pathogenic TSHR autoantibodies. Similarly, one of the TPO-responsive clones (clone 37 ) produces significant quantities of IL-4. Unlike murine clones, most human $\mathrm{Th} 2$ clones secrete a mixture of predominantly IL-4 with some IFN $\gamma$ and IL- 2 as well (4, $13,15,25)$. Not only are anti-TSHR and anti-TPO antibodies almost entirely $\operatorname{IgG}_{1}(39,40)$, but little IL-4 is required to promote the synthesis of this subclass in humans and is comparable with the levels observed in these clones (41). $\mathrm{IgG}_{1}$ is also relatively spared from the suppressive effect of IFN $\gamma$ on antibody production, particularly compared with the suppression of IgE synthesis, and even Th1-like clones can promote the synthesis of $\operatorname{IgG}_{1}(10,12,25,41)$. The release of IL-4 and IL-10 by the same $T$ cell provides another way of helping B cell responses, since this combination is synergistic in promoting $\mathrm{B}$ cell growth and differentiation (16). The presence of a mixture of Th1 and Th2 cells in an antibody-driven disease like GD is not unprecedented. Heterogeneity of cytokine release may even be a prerequisite for the recruitment of additional host cells into the affected tissue, the proliferation of IL-2-dependent but nonproducing Th2 cells, and the induction of antibody synthesis.

Based on the expression of HLA class II antigen by GD TEC, we previously proposed that cytokines such as IFN $\gamma$ could induce local upregulation of class II expression and antigen presenting capacity resulting in autoantigen presentation within the thyroid (42) perpetuated by mutual restimulation between autoreactive $T$ cells and TEC presenting autoantigens $(42,43)$. Since TEC can present influenza peptide to specific $T$ cell clones (44), restimulate TPO-specific T cells cloned from the same thyroid $(2,3)$, express cell surface accessory molecules like ICAM-I and LFA-3 $(45,46)$, and secrete IL-1 and IL-6 (47), they have many of the characteristics normally associated with APC, a capacity confirmed by other workers in the field (for example see reference 48 ). The ability of transfected EBVL, in this and previous studies, to effectively present endogenously synthesized TPO and TSHR supports the concept that cells expressing surface autoantigen ( such as TEC) could act as APC, as long as they also possess appropriate costimulatory properties. Since GD thyroid contains dendritic cells, it is also conceivable that the primary autoimmune response could be initiated either by professional APC presenting locally liberated antigen or by TEC assisted by third party "bystander" APC delivering the necessary costimuli (26). Suboptimal activation of naive $T$ cells by TEC might lead not to complete $\mathrm{T}$ cell inactivation or deletion but to alteration of the Th1/Th2 balance in their antigen-specific response $(26,49)$.

Despite the absence of a clear understanding of the initiating events, it is evident that the thyroid microenvironment contains all of the components required for an ongoing autoimmune response; class II-expressing TEC capable of restimulating $T$ cells, other APC, autoreactive $\mathrm{T}$ cell clones able to release IFN $\gamma$ upon stimulation with processed TPO or TSHR, and other clones which proliferate poorly to TSHR but secrete IL-4 and IL-10 thus promoting the synthesis of pathogenic autoantibodies. Ongoing work using modified culture and screening techniques should facilitate the identification of additional TSHRresponsive clones and should help define the functional characteristics and the range of autoantigenic epitopes recognized.
These analyses may eventually permit the development of antigen-specific immunotherapy.

\section{Acknowledgments}

We wish to acknowledge the helpful technical advice of Drs. N. R. Chu, G. Murison, A. Corcoran, S. Quaratino, and B. Foxwell. We are grateful to Prof. P. Bell, Mr. M. Thomas, Dr. B. Rapoport, and Dr. R. James for their ongoing interest in our work. The assistance of Dr. M. Kahan with FACS ${ }^{\circledR}$ analysis is greatly appreciated.

This work was supported by the Arthritis and Rheumatism Council, the Wellcome Trust, and Anergen, Inc. R. J. Mullins was supported by a Neil Hamilton Fairley Fellowship of the National Health and Medical Research Council of Australia.

\section{References}

1. McKenzie, J. M., and M. Zakarija. 1989. The clinical use of thyrotropin receptor antibody measurements. J. Clin. Endocrinol. Metab. 69:1093-1096.

2. Londei, M., G. F. Bottazzo, and M. Feldmann. 1985. Human T-cell clones from autoimmune thyroid glands: specific recognition of autologous thyroid cells. Science (Wash. DC). 228:85-89.

3. Dayan, C. M., M. Londei, A. E. Corcoran, B. Grubeck-Loebenstein, R. F. L. James, B. Rapoport, and M. Feldmann. 1991. Autoantigen recognition by thyroidinfiltrating T cells in Graves disease. Proc. Natl. Acad. Sci. USA. 88:7415-7419.

4. Mullins, R. J., Y. Chernajovsky, C. Dayan, M. Londei, and F. Feldmann.

1994. Transfection of thyroid autoantigens into Epstein-Barr virus transformed B cell lines: recognition by Graves' disease thyroid T cells. J. Immunol. 52:55725580 .

5. Rudensky, A. Y., P. Preston-Hurlburt, B. K. Al-Ramadi, J. Rothbard, and C. A. Janeway, Jr. 1992. Truncation variants of peptides isolated from MHC class II molecules suggest sequence motifs. Nature (Lond.). 359:429-431.

6. Chicz, R. M., R. G. Urban, J. C. Gorga, D. A. A. Vignali, W. S. Lane, and J. L. Strominger. 1993. Specificity and promiscuity among naturally processed peptides bound to HLA-DR alleles. J. Exp. Med. 178:27-47.

7. Mitchison, N. A. 1990. An exact comparison between the efficiency of two and three-cell type clusters in mediating helper activity. Eur. J. Immunol. 20:699702 .

8. Ewins, D. L., P. S. Barnett, R. W. S. Tomlinson, A. M. McGregor, and J. P. Banga. 1992. Mapping epitope specificities of monoclonal antibodies to thyroid peroxidase using recombinant antigen preparations. Autoimmunity. 11:141-149.

9. Chu, N. R., J. G. Murison, M. Londei, and M. Feldmann. 1994. T cells and thymocytes. In Protocols in Cell and Tissue Culture. J. B. Griffiths, A. Doyle, and D. G. Newell, editors. J. Wiley \& Sons, Chichester, United Kingdom. 21B:5.1-5.16.

10. Chambers, C. A., B. Zimmerman, and N. Hozumi. 1992. Functional heterogeneity of human $\mathrm{T}$ cells clones from atopic and non-atopic donors. Clin. Exp. Immunol. 88:149-156.

11. Haanen, J. B. A. G., R. de Waal Malefyt, P. V. C. M. Res, E. M. Kraakman, T. H. M. Ottenhoff, R. R. P. de Vries, and H. Spits. 1991. Selection of a human T helper type 1-like T cell subset by mycobacteria. J. Exp. Med. 174:583-592.

12. Spiegelberg, H. L., L. Beck, D. D. Stevenson, and G. Y. Ishioka. 1994. Recognition of $\mathrm{T}$ cell epitopes and lymphokine secretion by Rye grass allergen Lolium perenne I-specific human T cell clones. J. Immunol. 12:635-673.

13. Del Prete, G. F., A. Tiri, M. De Carli, C. Mastromauro, R. Biagiotti, D. Macchia, P. Falagiani, M. Ricci, and S. Romagnani. 1991. Purified protein derivative of mycobacterium tuberculosis and excretory-secretory antigen(s) of Toxocara canis expand in vitro human $\mathrm{T}$ cells with stable and opposite (type $1 \mathrm{~T}$ helper or type $2 \mathrm{~T}$ helper) profile of cytokine production. J. Clin. Invest. 88:346350 .

14. Seder, R. A., and W. E. Paul. 1994. Acquisition of lymphokine-producing phenotype by CD4 ${ }^{+} \mathrm{T}$ cells. Annu. Rev. Immunol. 12:635-673.

15. Maggi, E., P. Biswas, G. Del Prete, P. Parronchi, D. Macchia, C. Simonelli, L. Emmi, M. De Carli, A. Tiri, M. Ricci, and S. Romagnani. 1991. Accumulation of Th-2-like helper T cells in the conjunctiva of patients with vernal conjunctivitis. J. Immunol. 146:1169-1174.

16. Paliard, X., R. de Waal Malefyt, H. Yssel, D. Blanchard, I. Chretien, J. Abrams, J. E. de Vries, and H. Spits. 1988. Simultaneous production of IL-2, IL4 and IFN- $\gamma$ by activated human $\mathrm{CD}^{+}$and $\mathrm{CD}^{+} \mathrm{T}$ cell clones. J. Immunol. 141:849-855.

17. Umetsu, D. L., H. H. Jabara, R. H. DeKruyff, A. K. Abbas, A. J. S., and R. S. Geha. 1988. Functional heterogeneity among human inducer $T$ cell clones. J. Immunol. 140:4211-4216.

18. Hohlfeld, R., K. V. Toyka, K. Heininger, H. Grosse-Wilde, and I. Kalies. 
1984. Autoimmune human T-lymphocytes specific for acetylcholine receptor. Nature (Lond.). 310:244-246.

19. Martin, R., D. Jaraquemada, M. Flerlage, J. Richert, J. Whitaker, E. O Long, D. E. McFarlin, and H. F. McFarland. 1990. Fine specificity and HLA restriction of myelin basic protein-specific cytotoxic $\mathrm{T}$ cell lines from multiple sclerosis patients and healthy individuals. J. Immunol. 145:540-548.

20. Morita, T., N. Yoshikawa, F. Asasu, E. Resetkova, G. Arreaza, N. Miller, C. Jamieson, and R. Volpe. 1993. Studies of thyroid xenografts from Graves' disease in severe combined immunodeficient mice. J. Clin. Endocrinol. \& Metab. 77:255-261.

21. Macht, L., N. Fukuma, K. Leader, D. Sarsero, C. A. S. Pegg, D. I. W Phillips, P. Yates, S. M. McLachlan, C. Elson, and B. Rees Smith. 1991. Severe combined immunodeficient (SCID) mice: a model for investigating human thyroid autoantibody synthesis. Clin. Exp. Immunol. 84:34-42.

22. Portolano, S., S. McLachlan, and B. Rapoport. 1993. High affinity, thyroidspecific human autoantibodies displayed on the surface of filamentous phage use $\mathrm{V}$ genes similar to other autoantibodies. J. Immunol. 151:2839-2851.

23. Van Reijsen, F. C., C. A. F. M. Bruinzeel-Koomen, F. S. Kalthoff, E. Maggi, S. Romagnani, J. K. T. Westland, and G. C. Mudde. 1992. Skin-derived aeroallergen-specific $\mathrm{T}$-cell clones of Th2 phenotype in patients with atopic dermatitis. J. Allergy Clin. Immunol. 90:184-192.

24. Mosmann, T. R., H. Cherwinski, M. W. Bond, M. A. Gieglin, and R. L. Coffman. 1986. Two types of murine helper $T$ cell clones. I. Definition according to profiles of lymphokine activities and secreted proteins. J. Immunol. 136:23482357.

25. Wierenga, E. A., M. Snoek, C. De Groot, I. Chretien, J. D. Bos, H. M Jansen, and M. L. Kapsenberg. 1990. Evidence for compartmentalization of functional subsets of $\mathrm{CD}^{+} \mathrm{T}$ lymphocytes in atopic patients. J. Immunol. 144:4651 4656.

26. St Louis, J. D., J. A. Lederer, and A. H. Lichtman. 1993. Costimulatordeficient antigen presentation by an endothelial cell line induces a nonproliferative $T$ cell activation response without anergy. J. Exp. Med. 178:1597-1605.

27. Tandon, N., M. A. Freeman, and A. P. Weetman. 1992. T cell response to synthetic TSH receptor peptides in Graves' disease. Clin. Exp. Immunol. 89:468-473.

28. Sakata, S., S.-I. Tanaka, K. Okuda, K. Miura, T. Manshouri, and M. Z. Atassi. 1993. Autoimmune T-cell recognition sites of human thyrotrophin receptor in Graves' disease. Mol. Cell. Endocrinol. 92:77-82.

29. Swain, S. L., A. D. Weinberg, M. English, and G. Huston. 1990. IL-4 directs the development of Th2-like helper effectors. J. Immunol. 145:3796-3806.

30. Le Gros, G., S. Z. Ben-Sasson, R. Seder, F. D. Finkelman, and W. E. Paul. 1990. Generation of interleukin-4 (IL-4)-producing cells in vivo and in vitro: IL-2 and IL-4 are required for in vitro generation of IL-4-producing cells. J. Exp. Med. 172:921-929.

31. Noelle, R. J., J. Daum, W. C. Bartlett, J. McCann, and D. M. Shepherd. 1991. Cognate interactions between helper T cells and B cells. V. Reconstitution of $\mathrm{T}$ helper cell function using purified plasma membranes from activated $\mathrm{Th} 1$ and Th2 T helper cells and lymphokines. J. Immunol. 146:1118-1126.

32. Schmitz, J., M. Assenmacher, and A. Radbruch. 1993. Regulation of T helper cell cytokine expression: functional dichotomy of antigen-presenting cells. Eur. J. Immunol. 23:191-199.

33. De Wit, D., M. Man Meclelen, M. Ryelandt, A. C. Figueiredo, D. Abramowicz, M. Goldman, H. Bazin, J. Urbain, and O. Leo. 1992. The injection of deaggregated gamma globulins in adult mice induces antigen-specific unresponsiveness of T helper type 1 but not type 2 lymphocytes. J. Exp. Med. 175:9-14.
34. Romagnani, S. 1994. Lymphokine production by human T cells in disease states. Annu. Rev. Immunol. 12:227-257.

35. Swain, S. L. D. T. McKenzie, A. D. Weinberg, and W. Hancock. 1988 Characterization of $\mathrm{T}$ helper 1 and 2 cells subsets in normal mice; helper $\mathrm{T}$ cells responsible for $\mathrm{IL}-4$ and $\mathrm{IL}-5$ production are present as precursors that require priming before they develop into lymphokine-secreting cells. J. Immunol. 141:3445-3455.

36. Kamogawa, Y., L. E. Minasi, S. R. Carding, K. Bottomly, and R. A. Flavell. 1993. The relationship of IL-4 and IFN $\gamma$-producing $\mathrm{T}$ cells studies by linear ablation of IL-4-producing cells. Cell. 75:989-995.

37. De Carlie, M., M. M. D'Elios, S. Mariotti, C. Marcocci, A. Pinchera, M. Ricci, S. Romagnani, and G. F. Del Prete. 1993. Cytolytic T cells with Th1-like cytokine profile predominate in retroorbital lymphocytic infiltrates of Graves' opthalmopathy. J. Clin. Endocrinol. \& Metab. 77:1120-1124.

38. Del Prete, G. F., I. Tiri, S. Mariotti, A. Pinchera, M. Ricci, and S. Romagnani. 1987. Enhanced production of $\gamma$-interferon by thyroid-derived $T$ cells clones from patients with Hashimoto's thyroiditis. Clin. Exp. Immunol. 69:323331.

39. Weetman, A. P., M. E. Yateman, P. A. Ealey, C. M. Black, C. B. Reimer R. C. Williams, B. Shine, and N. J. Marshall. 1990. Thyroid-stimulating antibody activity between different immunoglobulin G subclasses. J. Clin. Invest. 86:723727.

40. Weetman, A. P., P. G. Byfield, C. Black, and C. B. Reimer. 1990. IgC heavy-chain subclass restriction of thyrotropin-binding inhibitory immunoglobulins in Graves' disease. Eur. J. Clin. Invest. 20:406-410.

41. Snapper, C. M., F. D. Finkelman, and W. E. Paul. 1988. Differentia regulation of $\mathrm{IgG}_{1}$ and $\mathrm{IgE}$ synthesis by interleukin 4. J. Exp. Med. 167:183196.

42. Bottazzo, G. F., R. Pujol-Borrell, T. Hanafusa, and M. Feldmann. 1983. Hypothesis: role of aberrant HLA-DR expression and antigen presentation in the induction of endocrine autoimmunity. Lancet. ii:1115-1119.

43. Grubeck-Loebenstein, B., M. Londei, C. Greenall, K. Pirich, W. Kassal W. Waldhausl, and M. Feldmann. 1988. Pathogenetic relevance of HLA-class IIexpressing thyroid follicular cells in nontoxic goiter and in Graves' disease. $J$. Clin. Invest. 81:1608-1614.

44. Londei, M., J. R. Lamb, G. F. Bottazzo, and M. Feldmann. 1984. Epithelial cells expressing aberrant MHC class II determinants can present antigen to cloned human T cells. Nature (Lond.). 312:639-641.

45. Weetman, W. P., S. Cohen, M. W. Makgoba, and L. K. Borysiewicz. 1989. Expression of an adhesion molecule, ICAM-1 by human thyroid cells. $J$. Endocrinol. 122:185-191.

46. Zheng, R. Q. H., E. R. Abney, B. Grubeck-Loebenstein, C. Dayan, R. N. Maini, and M. Feldmann. 1990. Expression of intercellular adhesion molecule-1 and lymphocyte function-associated antigen-3 on human thyroid epithelial cells in Graves' and Hashimoto's diseases. J. Autoimmun. 3:727-736.

47. Zheng, R. Q. H., E. R. Abney, C. Q. Chu, M. Field, B. GrubeckLoebenstein, R. N. Maini, and M. Feldmann. 1991. Detection of interleukin-6 and interleukin-1 production in human thyroid epithelial cells by non-radioactive in situ hybridization and immunohistochemical methods. Clin. Exp. Immunol. 83:314-319.

48. Mackenzie, W. A., A. E. Schwartz, E. W. Friedman, and T. F. Davies. 1987. Intrathyroidal $\mathrm{T}$ cell clones from patients with autoimmune thyroid disease. J. Clin. Endocrinol. \& Metab. 64:818-824.

49. Tandon, N., R. A. Metcalfe, D. Barnett, and A. P. Weetman. 1994. Expression of the costimulatory molecules B7/BB1 in autoimmune thyroid disease. $Q$. J. Med. 87:231-236. 